\title{
Developing the continuum of dental education: including dental foundation trainers in the delivery of a community-based clinical teaching programme
}

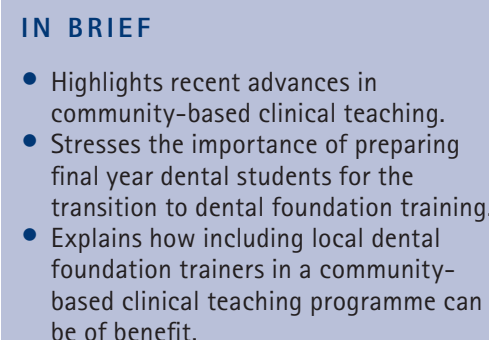

\author{
C. D. Lynch, ${ }^{1}$ P. J. Ash, ${ }^{2}$ B. L. Chadwick, ${ }^{3}$ R. A. Herbert ${ }^{4}$ and J. G. Cowpe ${ }^{5}$
}

Introduction Despite advances in evidence-based dental school educational programmes, the charge is sometimes made that dental students are 'no longer as good as they used to be.' Recent modifications have meant that dental education is now a 'life-long experience', of which dental school is the initial, albeit very important, component. Contemporary dental students will normally enter dental foundation (DF) training on completion of dental school. As such there may be value in including DF trainers in dental school teaching programmes. The aim of this paper is to report the experiences, feedback and opinions of these DF trainers following their first-hand experience of the community-based clinical teaching programme at Cardiff, and assess if their perspectives of contemporary dental student education changed following this. Materials and methods DF trainers were invited to attend the community-based clinical teaching programme at Cardiff on an observer basis. Twenty-four DF trainers attended, following which evaluation questionnaires were completed. Information sought included opinions and attitudes to the teaching programme, the physical environment in which the teaching programme took place, knowledge and attitudes towards community-based clinical teaching and modifications that DF trainers would make to the teaching programme to further improve the knowledge, skills and attributes of dental school graduates for DF training. Results Responses were received from $20 \mathrm{DF}$ trainers (response rate $=83 \%$ ). All 20 respondents felt that the teaching provided within the community-based clinical teaching programme was appropriate, with one respondent noting that it was like 'a day in the life of a dental practice', 'where anything could present'. Sixteen respondents were satisfied with the scope and content of the community-based clinical teaching programme, with a small number recommending inclusion of teaching in relation to inlays/onlays $(n=2)$, simple orthodontics $(n=1)$ and splinting $(n=1)$. Eighteen respondents reported that they felt students were adequately prepared for entry into DF training. All 20 respondents reported that their visit to the community-based clinical teaching programme had improved their perception of contemporary dental school education with one respondent noting: 'I am certainly more confident about students graduating' and another noting: 'It has reassured me that there are final year dental students that appear very professional and competent.' Conclusions This investigation has demonstrated there is much to be gained by inclusion of DF trainers in undergraduate dental student community-based clinical teaching programmes. In an era where tensions exist between dental school teaching and subsequent DF training and independent practice, inclusion of DF trainers can exert positive pressures on dental school programmes and on DF training to ensure that young and newly graduating dentists are best prepared to meet the needs of their patients.

\section{INTRODUCTION}

Dental foundation (DF) training, formerly known as 'vocational training', is a very

*Senior Lecturer/Honorary Consultant in Restorative Dentistry, School of Dentistry, Cardiff University, Cardiff; ${ }^{2}$ Consultant/Director of Primary Dental Care Teaching Units, St David's Primary Dental Care Unit, St David's Hospital, Cardiff; ${ }^{3}$ Professor/Honorary Consultant in Paediatric Dentistry, School of Dentistry, Cardiff University, Cardiff; ${ }^{4}$ Associate Dean and Foundation Training Director, Wales Deanery, School of Postgraduate Medical and Dental Education, Cardiff University, Cardiff: ${ }^{5}$ Director, Dental Postgraduate Education in Wales, Cardiff University, Cardiff

${ }^{*}$ Correspondence to: Dr Christopher D. Lynch

Email: lynchcd@cardiff.ac.uk

\section{Refereed Paper}

Accepted 10 October 2012

DOI: 10.1038/sj.bdj.2012.1039

${ }^{\circledR}$ British Dental Journal 2012; 213: 517-521 important step in the development of a dental practitioner who wishes to become capable of practising independently within the United Kingdom. From its beginnings, first as a voluntary arrangement in 1987, and latterly as a requirement for those seeking to provide care for NHS/GDS patients from 1993, DF training has provided an important transition from the relatively sheltered environment of dental school to that of the rigours and demands of general dental practice. As well as consolidation of skills and knowledge gained in dental school, DF training seeks to move the new graduate forward, with an emphasis, among others, of further developing important 'practice-related' skills, including complaints handling, audit, team working, communication etc. Within the UK, DF training is administered by the 12 postgraduate deaneries in England and one each in Scotland, Wales and Northern Ireland and currently there are in excess of 1,000 dental foundation trainees across the UK.

When considering the importance of DF training, one must first realise that the nature of dental education has changed considerably in recent years. At one time, dental education was a one-stage 'startstop' process, whereby education commenced on the first day of dental school and ceased at graduation. While further educational opportunities existed for dentists, 
these were discretionary on the part of the practitioner concerned. However, in recent times, the concept of the 'life-long learner' has become accepted within the profession. This is to be welcomed and places an emphasis on a career-long acquisition of new knowledge and skills, along with updating and refreshment of important subjects, supported increasingly by personal development plans. Thus, in the more modern approach to dental education, learning commences on the first day of dental school and usually ceases at retirement. This has become all the more apparent since the introduction of more formal continuing professional development (CPD) for UK dentists over the past ten years and the desire to introduce revalidation for UK dentists in the near future. As part of the process of developing a competent and 'fit-for purpose' dentist, DF training is an important milestone as the developing dental professional moves from dental school to independent practise. This has been further recognised in the recent reconfiguration of the Joint Committee for Specialist Training in Dentistry (JCSTD) into the Joint Committee for Postgraduate Training in Dentistry (JCPTD) with separate reporting Advisory Boards relating to Specialist Training in Dentistry (ABSTD) and Foundation Training in Dentistry (ABFTD). The remit of ABFTD includes, among others, DF training. The issues around quality assurance of DF training can now be more formally considered, within this important framework of postgraduate dental education, through this new advisory board.

However, tensions exist within this continuum of dental education, most notably at the transition of dental students from dental school to DF training, and subsequently as the new graduate emerges into dental practice as a 'young dentist'. Using an oft-cited claim that dental students are no longer 'as good as they used to be', there appear to be on occasions, divergence between the skills and knowledge gained at dental school and those expected of new graduates by DF trainers and employers in dental practice. ${ }^{1-3}$ Many of the reasons for such tensions may be assigned to those involved in administering dental school curricula and the expectations/current practising habits of DF trainers and subsequent employers.
In an attempt to overcome some of the perceived shortfalls of contemporary dental student education such as patient mix, leading dental teams in the delivery of holistic patient care and dealing with the 'business of dentistry' (eg clinical audit), many UK dental schools have developed community-based clinical teaching programmes (sometimes termed 'outreach teaching').4-12 Situated away from the base dental school, in either purpose-built units or dispersed practices, these programmes aim to give students (often close to graduation) an opportunity to practise dentistry in an environment that simulates that which they will experience at graduation, while still in a closely 'protected' environment. The benefits of such programmes have previously been highlighted, with these being popular among student and graduate dentists and DCPs, as well as increasing student confidence in performing their clinical skills.

\section{THE CARDIFF/WALES EXPERIENCE}

The Cardiff community-based clinical teaching programme began in 2002.,9-12 Situated close to the city centre in an area of high clinical need, a 12 chair purposebuilt unit was opened at the St David's Hospital and provides teaching for final year student dentists and DCPs. During the past academic year, a second, larger, 18 chair purpose-built facility has opened at Mountain Ash/Cynon Valley, approximately 20 miles away from the base dental school.

In Wales, the majority of DF year one training placements are within general dental practice. In 2012, 74 placements were funded through the Welsh Government. Five of these places are based in a foundation training practice at the Baglan Resource Centre, near Port Talbot. In addition, there are five Welsh Government funded DF1 posts and five hospital-based posts contributing to the Porth foundation training practice scheme. These trainees spend part of their time in the training unit and part of their time in the secondary care environment within the Cardiff Dental Hospital over a two year period. The two new training units came online in 2009, and in 2010 there was a further increase of six DF year one posts in Wales.

The Continuing Dental Education Committee (CDEC) provides a forum for liaison between the senior teachers in the
Dental School and the senior administration of the local DF training scheme. It meets three times a year on a formal basis to discuss and review matters of mutual interest.

\section{AIM}

As part of an initiative to further enhance and emphasise the links between dental school education and DF training in Wales, an invitation was extended to current DF trainers to attend and observe the community-based clinical teaching programme at the St David's Hospital, Cardiff. The aim of this paper is to report the experiences, feedback and opinions of these DF trainers following their experience at the community-based clinical teaching programme, and how their perspectives of contemporary dental student education changed following this.

\section{MATERIALS AND METHODS}

In Spring 2011, an invitation was issued to the $69 \mathrm{DF}$ trainers within the Welsh Postgraduate Deanery to attend the community-based clinical teaching programme at the St David's Hospital and to observe teaching within the unit. Thirty expressions of interest were received. Capacity was available for 24 of these DF trainers to attend. The trainers spent one day each at the community-based clinical teaching programme, where they shadowed the existing teachers and observed dental students interacting with teachers and providing care for their patients. Only one DF trainer attended on any one day. The days selected were 'routine' teaching days within the programme. At the end of this day, DF trainers were invited to complete a short questionnaire to evaluate their experience. Topics covered included:

- Opinions on the physical environment in which teaching took place

- Opinions on the existing teaching programme

- Knowledge and attitudes of DF trainers to community-based clinical teaching

- How the perspectives of DF trainers had changed in relation to dental school education as a result of their period of observation

- Modifications/changes that DF trainers would suggest to the community-based clinical teaching programme with the aim of best preparing dental school graduates for DF training. 
Questions were 'open' in design: respondents were given space in which to write a textual response. Respondents were informed that participation in this programme evaluation was voluntary. Data were entered anonymously onto an electronic database. Descriptive statistics are reported.

\section{RESULTS}

Responses were received from 20 of the 24 DF trainers who attended the community-based clinical teaching programme (response rate $=83 \%$ ).

\section{The physical environment}

All respondents felt that the facilities within the St David's Primary Dental Care Unit were suitable for the community-based clinical teaching programme. One respondent noted: 'excellent equipment and materials. Ample study room and seminar space.'

All respondents felt that the environment, within the teaching unit, lent itself well to good teaching. One respondent noted: 'the clinic felt busy and I was impressed by the variety of clinical procedures being carried out and by the students'. Another noted: 'good atmosphere between staff and students', while a third noted: 'good introduction to general practice'.

All respondents felt that supervisory staff delivered their teaching well and that they were approachable. Some comments of note included: 'the students enjoy the sense of 'freedom' but with clinical staff present' and 'all students seem very comfortable with staff members and the staff were supportive of the students.

\section{The teaching programme}

All respondents felt that the teaching provided within the community-based clinical teaching programme was appropriate. One respondent noted: 'students had exposure to wide range of treatments'. Another reported that the unit was: 'like 'a day in the life of a dental practice' where anything could present'.

When asked if there were any clinical treatments that appear not to be included that should have been, 16 respondents noted that they were satisfied with what they understood to be included. Others noted some minor concerns that students did not seem to gain clinical experience in

Table 1 Comments from DF trainers on what they feel are the advantages of communitybased clinical teaching programmes in comparison to 'traditional' dental school training Advantages of community-based clinical teaching: comments of DF trainers

'A stepping stone to practice'

'Fills a gap between dental school and practice. I know the students find it beneficial'

'There is less time wastage due to few students being on clinic. There is a good ratio of students to teachers'

'Probably closer to general practice environment, especially if students can start and complete treatment plans on individual patients'

'Can be managed more akin to a large general dental practice leading to greater efficiency - in turn leading to a more effective working and learning environment'

'Great advantage, it takes the student to the real world and gives an in-depth view into general practice'

'The outside world 'GDP practices' are not departmentalised hence this outreach centre mimics the scenarios you would have out there'

'They are nearer to the environment that they will encounter in practice'

inlays/onlays (two respondents), splinting procedures (one respondent) and simple orthodontics (one respondent).

All respondents reported that they felt the dental students were receiving what they considered to be an appropriate level of experience relative to their stage in the dental school programme. One respondent noted: 'my impression was that [the students] are getting more case load than I expected'. However, in contrast, one respondent noted: 'the experience levels could always be better. I believe in quantity helping competency'.

All respondents reported that they felt that the existing staff:student ratio within the teaching programme (1:6) was appropriate. One respondent noted: 'the ratio is appropriate - to cope with more than 1:6 would be challenging' while another noted that the ideal staff:student ratio 'depends upon experience of the student and complexity of cases throughout the day. However, 1:4 or 1:3 I feel would be optimum, particularly if outreach was extended to more junior undergraduates'.

Eighteen respondents (90\%) reported that they felt that the students were adequately prepared by the teaching programme, for entry into dental foundation training. Of those two respondents who took the view that the students were not adequately prepared, one felt that students needed 'more experience in endodontics, surgical and bridgework'. The other respondent noted 'each F1 [formerly known as 'vocational trainee'] has mentioned they would like more clinical experience and I feel they would benefit from more'
Knowledge and attitudes to community-based clinical teaching

DF trainers were asked to comment on what they felt were the advantages of community-based clinical teaching programmes over 'traditional' dental school training. A representative sample of the more interesting responses is reported in Table 1.

DF trainers were then asked for their views on whether students should be focusing on providing 'total patient care' within community-based clinical teaching or if they should instead focus on trying to increase numbers/ totals/targets of specific items of treatment (for example, numbers of crowns/RPDs/ extractions). Eight respondents felt that students should focus on providing 'total patient care', three respondents felt students should focus on completing numbers of treatments, while eight respondents felt a system encompassing both 'total patient care' and numbers of treatment was appropriate. One respondent did not express a view in this regard. Some of the interesting comments in relation to this debate included one respondent supporting 'total patient care', who noted: 'providing total care is more realistic of general dental practice, so the outreach programme is excellent in this respect'. Another respondent who supported this view wrote: 'total patient care is better as increase in numbers can be gained in F1 [vocational training]'. However, a contrasting view was expressed by another respondent, who noted: 'I believe in numbers'.

\section{General comments}

All respondents reported that their visit to the community-based clinical teaching programme had improved/changed their 
perception of contemporary dental school education in a positive way. Some of the more striking comments made by respondents are reported in Table 2.

Eighteen respondents (90\%) expressed a desire to becoming involved in dental student education within a community-based clinical teaching programme.

Respondents were then asked for views on how the community-based clinical teaching programme could be modified to further improve dental student preparation for DF training. A representative sample of responses is included in Table 3.

\section{DISCUSSION}

The results of this paper are interesting and heartening for those involved in dental education, as it demonstrates a commitment and enthusiasm on the part of those involved in both undergraduate and postgraduate dental education. Tensions often exist around dental school education and skills that are expected of DF trainees and young dentists by qualified practitioners, with concern often being expressed that dental students are "no longer as good as they used to be..$^{1-3}$ It is hoped that the development of programmes, such as the ones in place in Wales, will help overcome these tensions, and in particular, the lack of understanding (on both sides) which can lead to these issues.

The source of tension exists at the divergence of dental school teaching and what is considered to be 'accepted practice' among established general dental practitioners. Examples include the modern management of dental caries (for example, the removal of 'infected' versus 'affected' dentine), ${ }^{13}$ the practice of minimally invasive dentistry via the increased placement of posterior composite restorations, ${ }^{14-17}$ the repair, rather than replacement of defective composite restorations, ${ }^{18-21}$ and provision of metalbased removable partial dentures. ${ }^{22,23}$ Other examples of potential tension include the divergence in how best student experiences should be enhanced, either by focusing on total patient care, or the acquisition of targeted numbers of treatments. Targets/quotas/requirements are increasingly viewed as a historical approach to dental student education, with it being increasingly considered preferable that the achievement of competency/proficiency whilst managing the 'total patient care'/holistic care of an

Table 2 Some comments from the DF trainers in relation to how their visit to the community-based clinical teaching programme had changed their perception in a positive way of contemporary dental school education

How the visit to the community-based clinical teaching has changed the views of DF trainers

'It has reassured me that there are final year dental students that appear very professional and competent'

'It has given me insight into the aims of the outreach centre and is helpful to understand how the DF [vocational trainee] turns up on 'day one' in practice'

'I am certainly more confident about students graduating'

'I realised how much has changed [in dental education] in ten years!'

'I feel it's a good way of 'breaking students in' and getting them ready for their next level'

'Improved my understanding of how the students are taught. Impressed with the student / teacher relationship'

'Very modern'

Table 3 Views of DF trainers on how the community-based clinical teaching programme could be modified to further improve dental student preparation for DF training

Views of DF trainers on how the community-based clinical teaching programme could be modified to further improve dental student preparation for DF training

'Perhaps over the last one or two courses of treatment, provide a UDA analysis to provide insight in to the NHS remuneration system'

'I think some non-registered emergency cases could be seen that would enhance experience of treating patients in severe pain'

'I think that the outreach is covering all bases as best it can in preparation for DF1 [vocational training]'

'Focus on the 'bridge' between academia and F1/general dental practice'

'Continue to break barriers between undergrad and postgrad education by involving trainers in undergraduate training (or vice versa)?'

individual patient is a suitable way forward. This is also particularly true in an era when proposed changes to the funding contracts in primary dental care, in light of the Steele report, will focus on the overall achievement of 'health' rather than a fee-per-itembased care system. ${ }^{24}$

Sharing of educational experiences between dental school teachers and DF trainers should help ease such potential sources of tension as areas of change/ divergence can be identified. This is particularly evident in the comment of one respondent to this survey who noted: ' $I$ realised how much has changed [in dental education] in ten years!'. Apart from highlighting areas of divergence in teaching, a significant opportunity exists in opening dental student education programmes to those involved in DF training and beyond. Pressures can be exerted in both directions - on both dental student training and DF training. DF trainers can become more aware of advances in dental school teaching and evidence-based teaching, while dental school programmes can be modified to take account of the challenges in contemporary general dental practice.

However, while there have been tensions caused by changes in dental school teaching, there is also concern that the experiences of some dental students are less than ideal. An example of this includes the clinical experience of contemporary dental students. Most UK dental schools were situated in areas of high clinical need, however, as time has progressed many of these patients are now older and require simple restoration replacement and oral maintenance. While such patients are educationally used for less confident, junior students, they are not representative of the patient groups most new graduates will encounter. Another important area of perceived deficiency within 'traditional' dental school training relates to the socalled 'business of dentistry', where graduating dentists should be trained to lead the dental team in the environment in which they will work upon entering general dental practice, as well as the aspects of clinical audit and clinical governance.

Some DF trainers expressed opinions that students should complete inlays, 
splinting and simple orthodontics. Such opinions were based on what the trainers saw on the individual days they attended the unit. For clarity, inlays and splinting treatments are performed at the purpose built dental training units, but simple orthodontic treatments are not.

Associated with this depiction of tension between dental school teaching and subsequent practice, perhaps crystallised by the comment that a UDA analysis of treatments completed would be helpful, the question arises as to what UK dental schools should teach? Should they limit their teaching to treatments provided within NHS-funded dentistry, or should dental schools include new areas of teaching that, whilst challenging existing practice arrangements, is backed by a suitable evidence base? This poses important questions, which are necessary to consider when considering the future direction and development of dental practice within the UK.

Other interesting comments arising from this exercise include the debate on 'competence' versus 'numbers'. Historically, many schools required their students to complete a prerequisite number of treatments (that is, 'targets'/'requirements'/'totals') to meet the criteria for graduation. This has changed in recent times, partly encouraged by a drive towards 'competence', where a student demonstrates 'proficiency' in certain techniques and treatments, rather than completing a prescribed number of treatments. While this approach was reasonable to many respondents, one of the DF trainers noted: 'I believe in quantity helping competency', and another recorded: 'I believe in numbers'. These comments reflect the dilemma of contemporary dental school training. Do we treat a patient or do we have students repeating tasks? Proponents of the 'requirements' argument often feel that 'practice makes perfect'. However, with increased student numbers it would be very difficult to guarantee that every student would gain experience with sufficient numbers of patients and an appropriate number of clinical opportunities to complete the required number of treatments. Against this, proponents of the 'competences' argument suggest that 'quality' is better than 'quantity'
Perhaps a balance can found between both sides. At the School of Dentistry, Cardiff, students are required to complete 'competences' in a broad range of clinical procedures, while at the same time collect and record information on the numbers of treatments completed.

\section{CONCLUDING REMARKS}

It is important to realise that dental education is no longer a 'one-stage procedure' completed within an undergraduate dental school programme. Rather, learning commences on the first day of dental school and ceases at retirement or beyond. Within this context, community-based clinical teaching offers an exciting opportunity for the transition of dental students from dental school to DF training. However, by including DF trainers in community-based clinical teaching programmes, such those allied to Cardiff School of Dentistry, the potential exists to share knowledge and teaching experiences and in so doing, to improve the educational experiences for graduating dental students and young dental practitioners. Linked to this, another crucial challenge for dental schools in future years is the training of suitable 'leaders/directors' of communitybased clinical teaching. Given the investment in this form of teaching in recent years, it is unclear where future, suitable, 'leaders/directors' of community-based clinical teaching will come from. Further investigation of this important aspect of the interface between education and training at undergraduate and postgraduate levels is vital and is fully warranted.

We gratefully acknowledge the assistance of Ms Annette Woodyatt for her administrative support with this project.

1. Youngson C. Hindsight isn't always 20/20. Br Dent J 2012: 212: 473-474.

2. Buck D, Malik S, Murphy N et al. What makes a good dentist and do recent trainees make the grade? The views of vocational trainers. Br Dent J 2000; 189: 563-566.

3. Cabot $L B$, Radford D R. Are graduates as good as they used to be? Br Dent J 1999; 186: 318-319.

4. Lynch C D, Ash P J, Chadwick B L, Treasure E T. Community-based clinical teaching. Br Dent J 2009; 207: 141

5. Patel J, Fox K, Grieveson B, Youngson C C. Undergraduate training as preparation for vocational training in England: a survey of vocationa dental practitioners' and their trainers' views. Br Dent J 2006; 201: 9-15.

6. Craddock H L. Outreach teaching - the Leeds experience: reflections after one year. Br Dent J 2008;
204: $319-324$

7. Davies B R, Leung A N, Dunne S M. Perceptions of a simulated general dental practice facility - reported experiences from past students at the Maurice Wohl General Dental Practice Centre 2001 - 2008. Br Dent J 2009; 207: 371-376.

8. Smith $M$, Lennon M A, Brook A H, Robinson P G. A randomised controlled trial of outreach placement's effect on dental students' clinical confidence. J Dent Educ 2006; 70: 566-570.

9. Lynch C D, Ash P J, Chadwick B L. Student perspectives and opinions on their experience at an undergraduate outreach dental teaching centre at Cardiff: a 5-year study. Eur J Dent Educ 2010; 14: 12-16.

10. Lynch C D, Ash P J, Chadwick B L, Hannigan A. Effect of community-based clinical teaching programmes on student confidence: a view from the United Kingdom. J Dent Educ 2010; 74: 510-516.

11. Lynch C D, Ash P J, Chadwick B L, Hannigan A. Evaluation of a UK community-based clinical teaching/ outreach programme by former dental students two and five years after graduation. J Dent Educ 2010; 74: 1446-1152.

12. Lynch C D, Llewelyn J, Ash P J, Chadwick B L. Preparing dental students for independent careers as dental professionals: clinical audit and community-based clinical teaching. Br Dent J 2011; 210: $475-478$

13. Kidd E A. How 'clean' must a cavity be before restoration? Caries Res 2004; 38: 305-313.

14. Lynch C D, Frazier K B, McConnell R J, Blum I R, Wilson N H. State-of-the-art techniques in operative dentistry: contemporary teaching of posterior composites in UK and Irish dental schools. Br Dent J 2010: 209: 129-136.

15. Lynch C D, Frazier K B, McConnell R J, Blum I R, Wilson $\mathrm{N} \mathrm{H}$. Minimally invasive management of dental caries: contemporary teaching of posterior resin composite placement in US and Canadian dental schools. J Am Dent Assoc 2011; 142: $612-620$

16. Lynch C D, McConnell R J, Wilson N H. Challenges to teaching posterior composites in the United Kingdom and Ireland. Br Dent J 2006; 201: 747-750.

17. Gilmour A S, Latif M, Addy L D, Lynch C D. Placement of posterior composite restorations in United Kingdom dental practices: techniques, problems, and attitudes. Int Dent J 2009; 59: 148-154.

18. Blum I R, Lynch C D, Wilson N H. Teaching of direct composite restoration repair in undergraduate dental schools in the United Kingdom and Ireland. Eur J Dent Educ 2012: 16: e53-e58.

19. Blum I R, Lynch C D, Schriever A, Heidemann D, Wilson $\mathrm{N} \mathrm{H}$. Repair versus replacement of defective composite restorations in dental schools in Germany. Eur J Prosthodont Restor Dent 2011; 19: 56-61.

20. Blum I R, Lynch C D, Wilson N H. Teaching of the repair of defective composite restorations in Scandinavian dental schools. J Oral Rehabil 2012; 39: 210-216.

21. Lynch C D, Blum I R, Frazier K B, Haisch L, Wilson $\mathrm{NH}$. Repair or replacement of defective direct resin-based composite restorations: contemporary teaching in US and Canadian dental schools. J Am Dent Assoc 2012; 143: 157-163.

22. Lynch $C D$, Allen P F. Why do dentists struggle with removable partial denture design? An assessment of financial and educational issues. Br Dent J 2006; 200: 277-281.

23. Lynch $C D$, Allen P F. The teaching of removable partial dentures in Ireland and the United Kingdom. Br Dent J 2007; 203: E17.

24. Steele J S. NHS dental services in England. London: Department of Health, 2009. Online article available at http://www.dh.gov.uk/prod_consum_dh/ groups/dh digitalassets/documents/digitalasset/ dh_101180.pdf (accessed October 2012). 